International Journal of Pure and Applied Mathematics

Volume 85 No. 2 2013, 223-240

ISSN: 1311-8080 (printed version); ISSN: 1314-3395 (on-line version)

url: http://www.ijpam.eu

doi: http://dx.doi.org/10.12732/ijpam.v85i2.4

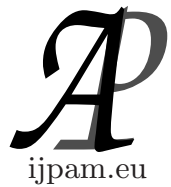

\title{
FUZZY CRITICAL PATH PROBLEM FOR PROJECT NETWORK
}

\author{
S. Elizabeth ${ }^{1 \S}$, L. Sujatha ${ }^{2}$ \\ ${ }^{1,2}$ Department of Mathematics \\ Auxilium College (Autonomous) \\ Vellore - 632 006, Tamil Nadu, INDIA
}

\begin{abstract}
The task of finding the crisp critical path has received researcher's attention over the past two decades which has wide range of applications in planning and scheduling the large projects. In most cases of our life, the data obtained for decision makers are only approximate, which gives rise to fuzzy critical path problem. In this paper, new ranking methods are introduced to identify the fuzzy critical path and the fuzzy critical length is presented in the nature of fuzzy membership function. The fuzzified version of the problem has been discussed with the aid of numerical example.
\end{abstract}

AMS Subject Classification: 90B10, 90B15, 90B50, 90C06

Key Words: fuzzy set theory, triangular fuzzy numbers (TFNs), fuzzy critical path analysis, project network, ranking methods

\section{Introduction}

The main aim of Government Agencies and Industrial Organizations is to plan their project in order to maximize resource utility and minimize over all cost. This type of management problem can be very well tackled using the network technique called critical path method. In reality, it is often difficult to ob-

Received: October 25, 2012

(c) 2013 Academic Publications, Ltd.

$\S$ Correspondence author url: www.acadpubl.eu 
tain estimates of activity time, due to the uncertainty of information as well as variation in the management scenario. Thus the conventional approaches tend to be less effective. Fuzzy set theory proposed by Zadeh [12] can play a significant role in this kind of decision making environment. Hence it is used to tackle problems where a source of vagueness is involved. Nasution [8] proposed a fuzzy critical path method by considering interactive fuzzy subtraction and by observing that only the non-negative part of the fuzzy numbers can have physical interpretation. Chanas and Zielinski [4] proposed a method to undertake critical path analysis of the network with fuzzy activity times by directly applying the extension principle [12] to the classical criticality notion treated as a function of activity duration time in the network. Slyeptsov and Tyshchuk [11] presented an efficient computation method of fuzzy time windows for late start and finish times of operations in the fuzzy network problems. Liang and Han [7] used the trapezoidal fuzzy numbers to make the fuzzy measures of activity times characterized by linguistic values and proposed an algorithm for finding the fuzzy critical path of a project network. Han et. al [5] employed the fuzzy critical path method to find out airport's ground critical operation processes where they utilized the ranking method developed by Liang and Han [7] to tackle ranking problems existing in fuzzy path analysis using trapezoidal fuzzy numbers, whereas in this paper, new ranking methods are proposed for fuzzy path analysis where the duration of activities are taken as triangular fuzzy numbers.

This paper is organized as follows: In Section 2, basic definitions and operations of fuzzy set theory have been reviewed and some new definitions are framed for fuzzy critical path method. Section 3, gives four different procedures to find out the fuzzy critical path using an illustrative example and finally Section 4 concludes the paper.

\section{Pre-Requisites}

\subsection{Triangular fuzzy number (see Bhowmik [1])}

Sometimes it may happen that some data or numbers cannot be specified precisely or accurately due to the error of the measuring technique or instruments etc. Suppose the height of a person is $160 \mathrm{~cm}$. But, practically it is impossible to measure the height accurately; actually this height is about $160 \mathrm{~cm}$; it is some more or less then $160 \mathrm{~cm}$. Thus the height of the person can be written more precisely as $(160-\gamma, 160,160+\delta)$ where $\gamma$ and $\delta$ are left and right spreads 
of 160. In general, this number can be written as $(a-\gamma, a, a+\delta)=\left(a_{1}, a_{2}, a_{3}\right)$. These types of numbers are called triangular fuzzy numbers and alternately represented as $(a, \gamma, \delta)$. The membership function definition of a triangular fuzzy number is given below.

Definition 1. A triangular fuzzy number $\tilde{A}$ can be defined by a triplet $(a, m, b)$ whose membership function is

$$
\mu_{\tilde{A}}(x ; a, m, b)= \begin{cases}\frac{x-a}{m-a}, & x \in[a, m) \\ 1, & x=m \\ \frac{b-x}{b-m}, & x \in(m, b] \\ 0, & x \notin[a, b]\end{cases}
$$

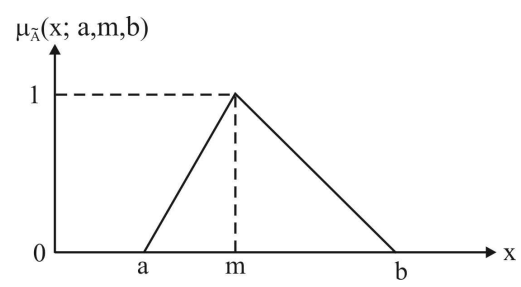

Figure 1: Triangular fuzzy number $\tilde{A}$

Definition 2. Let $\tilde{A}=(a, m, b)$ be a triangular fuzzy number. Then triangular beta possibility distribution function $\beta$ is defined as follows and its diagrammatic representation is given in Figure 2.

$$
\beta=\mu_{\tilde{A}}(x ; a, m, b)= \begin{cases}\left(\frac{x-a}{m-a}\right)^{(m-a) /(b-a)}\left(\frac{b-x}{b-m}\right)^{(b-m) /(b-a)}, & x \in(a, b) \\ 0, & x \notin(a, b) \\ & \end{cases}
$$

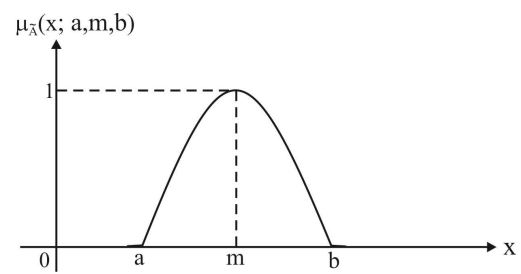

Figure 2: Beta possibility distribution function

It is given in Chanas [3] paper that the utility of Beta possibility distribution function may be verified in practice only. In this paper, it is found that it can be utilized to identify the critical path in fuzzy environment. 
Definition 3 ( $\alpha$-cut interval for triangular fuzzy number). [6] The $\alpha$-cut operation can be applied to the fuzzy number. If we denote $\alpha$-cut interval for fuzzy number $\tilde{A}=\left(a_{1}, a_{2}, a_{3}\right)$ as $A_{\alpha}$, the obtained interval $A_{\alpha}$ is defined as $A_{\alpha}=\left[a_{1}^{(\alpha)}, a_{3}^{(\alpha)}\right]=\left[\left(a_{2}-a_{1}\right) \alpha+a_{1},\left(a_{2}-a_{3}\right) \alpha+a_{3}\right]$.

Definition 4 (Addition Operation on $\alpha$-cut interval numbers). [6] If $A_{\alpha}=$ $\left[a_{1}^{(\alpha)}, a_{3}^{(\alpha)}\right]$ and $B_{\alpha}=\left[b_{1}^{(\alpha)}, b_{3}^{(\alpha)}\right]$ are the $\alpha$-cut interval for fuzzy numbers $\tilde{A}=$ $\left(a_{1}, a_{2}, a_{3}\right)$ and $\tilde{B}=\left(b_{1}, b_{2}, b_{3}\right)$ respectively.

Then $A_{\alpha}(+) B_{\alpha}=\left[a_{1}^{(\alpha)}+b_{1}^{(\alpha)}, a_{3}^{(\alpha)}+b_{3}^{(\alpha)}\right]$.

Definition 5 (Acyclic Digraph (Network)). A digraph is a graph each of whose edges are directed. An acyclic digraph is a digraph without cycle.

\subsection{Crisp graph with fuzzy weights (Type V), see [2]}

A fifth type of graph fuzziness occurs when the graph has known vertices and edges, but unknown weights (or Activity durations) on the edges. Thus only the weights are fuzzy.

Definition 6 (Maximum Operation). Let $\tilde{A}=\left(a_{1}, m_{1}, b_{1}\right)$ and $\tilde{B}=$ $\left(a_{2}, m_{2}, b_{2}\right)$ be two triangular fuzzy numbers. Then the maximum operation between $\tilde{A}$ and $\tilde{B}$ is denoted by

$$
\begin{aligned}
\tilde{L}_{\max }=(\tilde{A}, \tilde{B}) & =\left(\max \left(a_{1}, a_{2}\right), \max \left(m_{1}, m_{2}\right), \max \left(b_{1}, b_{2}\right)\right) \\
& =(a, m, b)
\end{aligned}
$$

Definition 7 (Fuzzy activity time of triangular fuzzy number). Fuzzy activity time is denoted by $F \tilde{A} T_{i j}$ of activity $A_{i j}$ in a project network is represented by a triangular fuzzy number $F \tilde{A} T_{i j}=\left(a_{i j}, m_{i j}, b_{i j}\right)$ where $a_{i j}, m_{i j}, b_{i j}$ are minimum, moderate and maximum values of assessing activity time for $A_{i j}$.

Definition 8 (Operations on two fuzzy activity time). Let $F \tilde{A} T_{1}=$ $\left(a_{1}, m_{1}, b_{1}\right)$ and $F \tilde{A} T_{2}=\left(a_{2}, m_{2}, b_{2}\right)$ be two fuzzy activity time.

(i) Addition Operation $(+)$ :

$F \tilde{A} T_{1}(+) F \tilde{A} T_{2}=\left(a_{1}, m_{1}, b_{1}\right)(+)\left(a_{2}, m_{2}, b_{2}\right)$

$$
=\left(a_{1}+a_{2}, m_{1}+m_{2}, b_{1}+b_{2}\right)
$$

(ii) Subtraction Operation $(-)$ :

$$
\begin{array}{r}
F \tilde{A} T_{1}(-) F \tilde{A} T_{2}=\left(a_{1}, m_{1}, b_{1}\right)(-)\left(a_{2}, m_{2}, b_{2}\right) \\
=\left(a_{1}-b_{2}, m_{1}-m_{2}, b_{1}-a_{2}\right)
\end{array}
$$

The following definitions are introduced in this paper. 


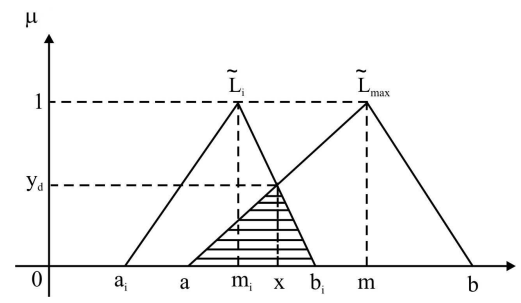

Figure 3: Acceptability index

Definition 9 (Decision Maker's Risk Index). For the fuzzy activity time $F \tilde{A} T_{i j}=\left(a_{i j}, m_{i j}, b_{i j}\right)$, the decision maker's risk index $\lambda$ can be obtained by

$$
\lambda=\left[\left.\sum_{\substack{i \\ A_{i j} \in S A}} \sum_{j} \frac{b_{i j}-a_{i j}}{\left(m_{i j}-a_{i j}\right)+\left(b_{i j}-m_{i j}\right)}\right|^{/ t}\right.
$$

Where 'SA' and ' $\mathrm{t}$ ' denote the set of all activities and the number of activities.

Definition 10 (Decision Maker's risk index ranking value). The ranking value $R\left(\tilde{L}_{i}\right)$ of the triangular fuzzy number $\tilde{L}_{i}=\left(a_{i}, m_{i}, b_{i}\right), i=1$ to $n$ can be obtained as follows:

$$
R\left(\tilde{L}_{i}\right)=\lambda\left[\left(b_{i}-x_{1}\right) /\left(x_{2}-x_{1}+b_{i}-m_{i}\right)\right]+(1-\lambda)\left[\left(x_{2}-a_{i}\right) /\left(x_{2}-x_{1}+m_{i}-a_{i}\right)\right]
$$

Where $\lambda$ is the decision maker's risk index.

$$
x_{1}=\min \left\{a_{1}, a_{2}, \ldots, a_{n}\right\} \text { and } x_{2}=\max \left\{b_{1}, b_{2}, \ldots, b_{n}\right\} .
$$

Definition 11 (Rules for ranking triangular fuzzy number). For two triangular fuzzy numbers $\tilde{L}_{1}$ and $\tilde{L}_{2}, \tilde{L}_{1}>\tilde{L}_{2}$ if and only if $R\left(\tilde{L}_{1}\right)<R\left(\tilde{L}_{2}\right)$ and $\tilde{L}_{1}=\tilde{L}_{2}$ if and only if $R\left(\tilde{L}_{1}\right)=R\left(\tilde{L}_{2}\right)$.

Definition 12 (Acceptability Index). Let $\tilde{L}_{i}=\left(a_{i}, m_{i}, b_{i}\right), i=1$ to $n$ and $\tilde{L}_{\max }=(a, m, b)$ be two triangular fuzzy numbers. If $a_{i} \leq a, m_{i} \leq m$, $b_{i} \leq b$ then the Acceptability Index between $\tilde{L}_{i}$ and $\tilde{L}_{\text {max }}$ can be calculated as $A\left(\tilde{\tilde{L}}_{\text {max }}>\tilde{L}_{i}\right)=\frac{b_{i}-a}{(m-a)+\left(b_{i}-m_{i}\right)}=y_{d}$.

Here $\tilde{L}_{1}>\tilde{L}_{2}$ if and only if $A\left(\tilde{L}_{\max }>\tilde{L}_{1}\right)>A\left(\tilde{L}_{\max }>\tilde{L}_{2}\right)$.

Consider the above Figure 3.

The above formula is obtained from [10].

Since $m_{i}<x<b_{i}$,

$$
y_{d}=\frac{b_{i}-x}{b_{i}-m_{i}} \Rightarrow\left(b_{i}-m_{i}\right) y_{d}=b_{i}-x
$$




$$
\Rightarrow x=b_{i}-\left(b_{i}-m_{i}\right) y_{d}
$$

Since $a<x<m$,

$$
\begin{aligned}
y_{d}=\frac{x-a}{m-a} & \Rightarrow(m-a) y_{d}=x-a \\
& \Rightarrow x=a+(m-a) y_{d}
\end{aligned}
$$

Equating (3) and (4)

$$
\begin{gathered}
b_{i}-\left(b_{i}-m_{i}\right) y_{d}=a+(m-a) y_{d} \\
\Rightarrow y_{d}=\frac{b_{i}-a}{(m-a)+\left(b_{i}-m_{i}\right)}
\end{gathered}
$$

Definition 13 (Totally dominating). If $A\left(\tilde{L}_{\max }>\tilde{L}_{i}\right)=1$, then $\tilde{L}_{\max }$ is said to be totally dominating over $\tilde{L}_{i}, i=1$ to $n$ in the sense of maximization.

Definition 14 (Partially dominating). If $0<A\left(\tilde{L}_{\max }>\tilde{L}_{i}\right)<1$, then $\tilde{L}_{\max }$ is said to be partially dominating over $\tilde{L}_{i}, i=1$ to $n$.

Definition 15 (Metric distance). Let $\tilde{A}=\left(a_{1}, m_{1}, b_{1}\right)$ and $\tilde{B}=\left(a_{2}, m_{2}, b_{2}\right)$ be two triangular fuzzy numbers. Then the metric distance between $A$ and $B$ can be calculated as follows:

$$
D(\tilde{A}, \tilde{B})=\left[\int_{0}^{1}\left[A_{L}(\alpha)-B_{L}(\alpha)\right]^{2} d \alpha+\int_{0}^{1}\left[A_{R}(\alpha)-B_{R}(\alpha)\right]^{2} d \alpha\right]^{\frac{1}{2}}
$$

Where $A_{L}(\alpha), A_{R}(\alpha)$ and $B_{L}(\alpha), B_{R}(\alpha)$ are $\alpha$-cut intervals of $\tilde{A}$ and $\tilde{B}$ respectively. Here $\alpha \in[0,1]$.

In order to rank fuzzy numbers, let us take the triangular fuzzy number $\tilde{B}=0$ then the metric distance between $\tilde{A}$ and 0 is calculated as follows:

$$
\begin{aligned}
D(\tilde{A}, 0) & =\left[\int_{0}^{1}\left[A_{L}(\alpha)\right]^{2} d \alpha+\int_{0}^{1}\left[A_{R}(\alpha)\right]^{2} d \alpha\right]^{\frac{1}{2}} \\
& =\left[\int_{0}^{1}\left[a_{1}-\left(m_{1}-a_{1}\right) \alpha\right]^{2} d \alpha+\int_{0}^{1}\left[b_{1}-\left(b_{1}-m_{1}\right) \alpha\right]^{2} d \alpha\right]^{\frac{1}{2}} \\
& =\left[\frac{a_{1}^{2}+b_{1}^{2}+2 m_{1}^{2}+m_{1}\left(a_{1}+b_{1}\right)}{3}\right]^{\frac{1}{2}}
\end{aligned}
$$

Here $\tilde{A}>\tilde{B}$ if and only if $D(\tilde{A}, 0)>D(\tilde{B}, 0)$. 


\section{Fuzzy Critical Path Method}

\subsection{Procedure for Fuzzy Critical Path Method Based on Decision Maker's risk index Ranking Value for TFNs}

Notations:

$N=$ The set of all nodes in a project network

$A_{i j}=$ The Activity between nodes $i$ and $j$

$F \tilde{E} T_{i j}=$ The fuzzy activity time of $A_{i j}$

$F \tilde{E} S_{j}=$ The earliest starting fuzzy time of node $j$

$F \tilde{L} F_{i}=$ The latest finishing fuzzy time of node $i$

$F \tilde{T} S_{i j}=$ The total slack fuzzy time of $A_{i j}$

$p_{k}=$ The $k^{\text {th }}$ fuzzy path

$P=$ The set of all fuzzy paths in a project network

$F C P M\left(p_{k}\right)=$ The total slack fuzzy time of path $p_{k}$ in a project network.

\subsection{Properties}

Property 3.1. (Forward Pass Calculation) It is employed to calculate the earliest starting fuzzy time in the project network.

Set the initial node to zero for starting i.e, $F \tilde{E} S_{1}=(0,0,0)$

$F \tilde{E} S_{j}=\max _{i}\left\{F \tilde{E} S_{i}(+) F \tilde{E} T_{i j}\right\}, j \neq 1, j \in N, i=$ number of preceding nodes.

Ranking value is utilized to identify the maximum value.

Earliest finishing fuzzy time $=$ Earliest starting fuzzy time $(+)$ Fuzzy activity time.

Property 3.2. (Backward Pass Calculation) It is employed to calculate the latest finishing time in the project network.

Set $F \tilde{L} F_{n}=F \tilde{E} S_{n}$.

$F \tilde{L} F_{i}=\min _{j}\left\{F \tilde{L} F_{j}(-) F \tilde{E} T_{i j}\right\}, i \neq n, i \in N, j=$ number of succeeding nodes.

Ranking value is utilized to identify the minimum value.

Latest starting fuzzy time = Latest finishing fuzzy time (-) Fuzzy activity time.

Property 3.3. For the activity $A_{i j}, i<j$

Total fuzzy Slack:

$F \tilde{T} S_{i j}=F \tilde{L} F_{j}(-)\left(F \tilde{E} S_{i}(+) F \tilde{E} T_{i j}\right)($ or $)\left(F \tilde{L} F_{j}(-) F \tilde{E} T_{i j}\right)(-) F \tilde{E} S_{i}$, 
$1 \leq i<j \leq n ; i, j \in N$.

Property 3.4. $F C P M\left(p_{k}\right)=\sum_{\substack{1 \leq i<j \leq n \\ i, j \in p_{k}}} F T S_{i j}, p_{k} \in P, p_{k}$ is the possible paths in a network from source node to the destination node, $k=1$ to $m$.

Property 3.5. In a project network, a path $p_{c}$ such that $F C P M\left(p_{c}\right)=$ $\max \left\{F C P M\left(p_{k}\right) / p_{k} \in P, k=1\right.$ to $\left.m\right\}$ is a fuzzy critical path. The fuzzy critical path length is the sum of the fuzzy activity time of the corresponding path $p_{c}$.

Step 1: Construct a project network defined by a directed acyclic graph $G(V, E)$, where $V$ is the set of vertices (or nodes) and $E$ is the set of edges (or arcs). Arcs and nodes represent activities and events respectively. If ' $l$ ' denotes the number of nodes and ' $q$ ' denotes the number of edges, then the graph $G(V, E)$ is demonstrated as a matrix $(A)_{l \times l}$. Matrix $(A)_{l \times l}$ is called the node-arc adjacency matrix for graph $G(V, E)$ (i.e) $A=\left[a_{i j}\right], i=1, \ldots, l$; $j=1, \ldots, l$.

$$
a_{i j}= \begin{cases}1, & \text { if there is an edge between } i^{t h} \text { and } j^{t h} \text { vertices } \\ -1, & \text { if there is an edge between } j^{t h} \text { and } i^{t h} \text { vertices } \\ 0, & \text { if there is no edges between them. }\end{cases}
$$

Step 2: Estimate the fuzzy activity time with respect to each activity.

Step 3: Let $F \tilde{E} S_{1}=(0,0,0)$ and calculate $F \tilde{E} S_{j}, j=2,3, \ldots, n$ by using Property 3.1.

Step 4: Let $F \tilde{L} F_{n}=F \tilde{E} S_{n}$ and calculate $F \tilde{L} F_{i}, i=n-1, n-2, \ldots, 2,1$ by using Property 3.2.

Step 5: Calculate $F \tilde{T} S_{i j}$ with respect to each activity in a project network by using Property 3.3.

Step 6: Find all the possible paths and calculate $F C P M\left(p_{k}\right)$ by using Property 3.4.

Step 7: Identify the critical path by using Property 3.5.

\section{Numerical Example 1}

To explain the proposed approach in a better way, an application is presented, which deals with the realization of a road connection between two famous cities in Tamil Nadu namely Chennai and Coimbatore. Linguistics terms such as 
"approximately between" and "around" can be properly represented by the approximate reasoning of fuzzy set theory [13]. Here triangular fuzzy numbers are used to describe the durations of each task of project. The use of triangular fuzzy numbers appears adequate, for it offers a good compromise between accuracy and computational time.

As a real time application of this model the following example is considered. The project manager wishes to construct a possible route from Chennai $(s)$ to Coimbatore $(d)$. Given a road map of Tamil Nadu on which the time taken between each pair of successive intersection are marked, to determine the critical path from source vertex ' $s$ ' to the destination vertex ' $d$ '.

Step 1: Construct a project network $G(V, E)$ with 8 vertices and 10 edges.

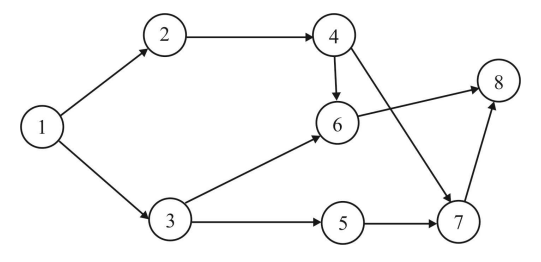

Figure 4: Fuzzy project network

Let vertex 1 be Chennai, vertex 2 be Vellore, vertex 3 be Villupuram, vertex 4 be Dharmapuri, vertex 5 be Perambalur, vertex 6 be Erode, vertex 7 be Karur, vertex 8 be Coimbatore.

For Figure 4, the network matrix is given below:

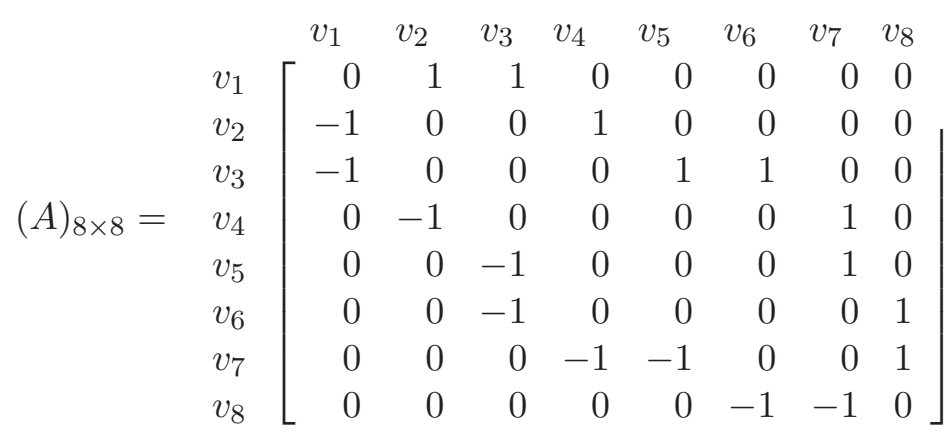

\section{Step 2:}

Step 3: The earliest starting fuzzy time $F \tilde{E} S_{1}=(0,0,0)$

$F \tilde{E} S_{2}=(0,0,0)(+)(2,3,4)=(2,3,4)$

$F \tilde{E} S_{3}=(0,0,0)(+)(1,3,4)=(1,3,4)$

$F \tilde{E} S_{4}=(2,3,4)(+)(1,3,5)=(3,6,9)$ 
Table 1: Activities and their fuzzy durations

\begin{tabular}{|c|c|}
\hline Activity & Fuzzy Activity Time \\
\hline $1-2$ & About 3 months $(2,3,4)$ \\
\hline $1-3$ & About 3 months $(1,3,4)$ \\
\hline $2-4$ & About 3 months $(1,3,5)$ \\
\hline $3-5$ & About 2 months $(1,2,3)$ \\
\hline $3-6$ & About 5 months $(2,5,7)$ \\
\hline $4-6$ & About 4 months $(3,4,6)$ \\
\hline $4-7$ & About 4 months $(3,4,5)$ \\
\hline $5-7$ & About 4 months $(1,4,5)$ \\
\hline $6-8$ & About 5 months $(2,5,6)$ \\
\hline $7-8$ & About 4 months $(3,4,7)$ \\
\hline
\end{tabular}

$$
\begin{aligned}
F \tilde{E} S_{5} & =(1,3,4)(+)(1,2,3)=(2,5,7) \\
F \tilde{E} S_{6} & =\max \{(3,6,9)(+)(3,4,6),(1,3,4)(+)(2,5,7)\} \\
& =\max \{(6,10,15),(3,8,11)\}
\end{aligned}
$$

By Equation (1) given in Definition $9, \lambda=0.1$ for $(6,10,15)$ and $(3,8,11)$.

Now, the ranking value of $(6,10,15)$ and $(3,8,11)$ can be obtained using Definition 10:

$$
\begin{aligned}
& x_{1}=3, x_{2}=15 \\
& \begin{aligned}
R((3,8,11))= & (0.1)[(11-3) /(15-3+11-8)] \\
& +(1-0.1)[(15-3) /(15-3+8-3)] \\
= & 0.05+0.64=0.69
\end{aligned} \\
& \begin{aligned}
R((6,10,15)) & =(0.1)[(15-3) /(15-3+15-10)] \\
& +(1-0.1)[(15-6) /(15-3+10-6)] \\
= & 0.07+0.51=0.58
\end{aligned} \\
& R((3,8,11))>R((6,10,15)) \Rightarrow F \tilde{E} S_{6}=(6,10,15) \\
& F \tilde{E} S_{7}=\max \{(3,6,9)(+)(3,4,5),(2,5,7)(+)(1,4,5)\} \\
& \quad=\max \{(6,10,14),(3,9,12)\}
\end{aligned}
$$

By Equation $(1), \lambda=0.1$ for $(6,10,14)$ and $(3,9,12)$. Now the ranking value of $(6,10,14)$ and $(3,9,12)$ can be obtained:

$$
\begin{aligned}
& x_{1}=3, x_{2}=14 \\
& R((6,10,14))=0.55 \text { and } R((3,9,12))=0.64 \\
& \therefore R((3,9,12))>R\left((6,10,14) \Rightarrow F \tilde{E} S_{7}=(6,10,14)\right. \\
& F \tilde{E} S_{8}=\max \{(6,10,15)(+)(2,5,6),(6,10,14)(+)(3,4,7)\} \\
& \quad=\max \{(8,15,21),(9,14,21)\} \\
& \lambda=0.1 \text { for }(8,15,21),(9,14,21) \text { and }
\end{aligned}
$$




$$
R((9,14,21))=0.67>R((8,15,21))=0.65 \Rightarrow F \tilde{E} S_{8}=(8,15,21) .
$$

Step 4: The latest finishing fuzzy time

$$
F \tilde{L} F_{8}=F \tilde{E} S_{8}=(8,15,21)
$$

$F \tilde{L} F_{7}=(8,15,21)(-)(3,4,7)=(1,11,18)$

$F \tilde{L} F_{6}=(8,15,21)(-)(2,5,6)=(2,10,19)$

$F \tilde{L} F_{5}=(1,11,18)(-)(1,4,5)=(-4,7,17)$

$F \tilde{L} F_{4}=\min \{(1,11,18)(-)(3,4,5),(2,10,19)(-)(3,4,6)\}$

$$
=\min \{(-4,7,15),(-4,6,16)\} \text {. }
$$

$\lambda=0.1$ for $(-4,7,15),(-4,6,16)$ and

$R((-4,7,15))=0.65<R((-4,6,16))=0.67 \Rightarrow F \tilde{L} F_{4}=(-4,6,16)$

$F \tilde{L} F_{3}=\min \{(-4,7,17)(-)(1,2,3),(2,10,19)(-)(2,5,7)\}$

$$
=\min \{(-7,5,16),(-5,5,17)\} \text {. }
$$

$\lambda=0.1$ for $(-7,5,16),(-5,5,17)$ and

$R((-5,5,17))=0.65<R((-7,5,16))=0.67 \Rightarrow F \tilde{L} F_{3}=(-7,5,16)$

$F \tilde{L} F_{2}=(-4,6,16)(-)(1,3,5)=(-9,3,15)$

$F \tilde{L} F_{1}=\min \{(-9,3,15)(-)(2,3,4),(-7,5,16)(-)(1,3,4)\}$

$$
=\min \{(-13,0,13),(-11,2,15)\}
$$

$\lambda=0.1$ for $(-13,0,13),(-11,2,15)$ and

$R((-11,2,15))=0.64<R((-13,0,13))=0.67 \Rightarrow F \tilde{L} F_{1}=(-13,0,13)$

\section{Step 5:}

Table 2: Total slack fuzzy time for each activity

\begin{tabular}{|c|c|c|c|c|}
\hline $\begin{array}{c}\text { Activity } \\
(i-j) i<j\end{array}$ & $\begin{array}{c}\text { Duration } \\
F \tilde{E} T_{i j}\end{array}$ & $F \tilde{E} S_{i}$ & $F \tilde{L} F_{j}$ & $F \tilde{T} S_{i j}$ \\
\hline $1-2$ & $(2,3,4)$ & $(0,0,0)$ & $(-9,3,15)$ & $(-13,0,13)$ \\
\hline $1-3$ & $(1,3,4)$ & $(0,0,0)$ & $(-7,5,16)$ & $(-11,2,15)$ \\
\hline $2-4$ & $(1,3,5)$ & $(2,3,4)$ & $(-4,6,16)$ & $(-13,0,13)$ \\
\hline $3-5$ & $(1,2,3)$ & $(1,3,4)$ & $(-4,7,17)$ & $(-11,2,15)$ \\
\hline $3-6$ & $(2,5,7)$ & $(1,3,4)$ & $(2,10,19)$ & $(-9,2,16)$ \\
\hline $4-6$ & $(3,4,6)$ & $(3,6,9)$ & $(2,10,19)$ & $(-13,0,13)$ \\
\hline $4-7$ & $(3,4,5)$ & $(3,6,9)$ & $(1,11,18)$ & $(-13,1,12)$ \\
\hline $5-7$ & $(1,4,5)$ & $(2,5,7)$ & $(1,11,18)$ & $(-11,2,15)$ \\
\hline $6-8$ & $(2,5,6)$ & $(6,10,15)$ & $(8,15,21)$ & $(-13,0,13)$ \\
\hline $7-8$ & $(3,4,7)$ & $(6,10,14)$ & $(8,15,21)$ & $(-13,1,12)$ \\
\hline
\end{tabular}

Step 6: The total slack fuzzy time of path $p_{k}$ in a project network: 
$F C P M\left(p_{k}\right)$

Find all the possible paths and calculate $F C P M\left(p_{k}\right)$ by using Property 3.4.

The possible paths are

$P=\{(1-2-4-6-8),(1-2-4-7-8),(1-3-6-8),(1-3-5-7-8)\}$

For Path $p_{1}: 1-2-4-6-8$

$F C P M\left(p_{1}\right)=F \tilde{T} S_{12}(+) F \tilde{T} S_{24}(+) F \tilde{T} S_{46}(+) F \tilde{T} S_{68}=(-52,0,52)$

For Path $p_{2}: 1-2-4-7-8$

$F C P M\left(p_{2}\right)=F \tilde{T} S_{12}(+) F \tilde{T} S_{24}(+) F \tilde{T} S_{47}(+) F \tilde{T} S_{78}=(-52,2,50)$

For Path $p_{3}: 1-3-6-8, F C P M\left(p_{3}\right)=(-33,4,44)$

For Path $p_{4}: 1-3-5-7-8, F C P M\left(p_{4}\right)=(-46,7,57)$

\section{Step 7:}

Table 3: Rank value of total slack fuzzy time of possible paths

\begin{tabular}{|c|c|c|c|}
\hline $\begin{array}{c}\text { Paths }\left(p_{k}\right) \\
k=1 \text { to } 4\end{array}$ & $\begin{array}{c}F C P M\left(p_{k}\right) \\
k=1 \text { to } 4\end{array}$ & $\begin{array}{c}\text { Rank Value } \\
R\left[\left(F C P M\left(p_{k}\right)\right)\right] \\
k=1 \text { to } 4, \lambda=0.1\end{array}$ & Ranking \\
& & $\begin{array}{c}k=-52, x_{2}=57 \\
x_{1}=-68\end{array}$ & 1 \\
\hline$p_{1}: 1-2-4-6-8$ & $(-52,0,52)$ & 0.68 & 2 \\
\hline$p_{2}: 1-2-4-7-8$ & $(-52,2,50)$ & 0.67 & 4 \\
\hline$p_{3}: 1-3-6-8$ & $(-33,4,44)$ & 0.61 & 3 \\
\hline$p_{4}: 1-3-5-7-8$ & $(-46,7,57)$ & 0.64 & 3 \\
\hline
\end{tabular}

Since $R\left(F C P M\left(p_{1}\right)\right)>R\left(F C P M\left(p_{2}\right)\right)>R\left(F C P M\left(p_{4}\right)\right)$

$>R\left(F C P M\left(p_{3}\right)\right)$

The critical path is

$p_{1}: 1-2-4-6-8=(2,3,4)(+)(1,3,5)(+)(3,4,6)(+)(2,5,6)$

$$
=(8,15,21)
$$

The project completed time is approximately 15 months.

\subsection{Procedure for Fuzzy Critical Path Problem Based on Beta Possibility Distribution Function for TFNs}

Step 1: Construct a network $G(V, E)$ where $V$ is the set of vertices, $E$ is the set of edges. Here $G$ is an acyclic digraph and edge weights (Activity durations) are taken as triangular fuzzy numbers.

Step 2: Calculate all the possible paths $p_{k}, k=1$ to $m$ from source vertex ' $s$ ' to the destination vertex ' $d$ ' and the corresponding path lengths 
$\tilde{L}_{k}=\left(a_{k}, m_{k}, b_{k}\right), k=1$ to $m$ using (i) of Definition 8 .

Step 3: For $x=\max \left\{m_{1}, m_{2}, \ldots, m_{k}\right\}$. Calculate the Beta Possibility distribution function $\beta_{k}=\mu_{\tilde{L}_{k}}\left(a_{k}, m_{k}, b_{k}\right)$ for each possible path lengths $\tilde{L}_{k}$, $k=1$ to $m$ using Definition 2 .

Step 4: The path having the maximum Beta possibility distribution function is identified as the critical path and the corresponding path length is the critical path length.

\section{Numerical Example 2}

For Figure 4, the results of the network is given in the below Table 4 .

Table 4: Results of the Network

\begin{tabular}{|c|c|c|c|}
\hline $\begin{array}{c}\text { Paths }\left(p_{k}\right) \\
k=1 \text { to } 4\end{array}$ & $\begin{array}{c}\text { Path lengths }\left(\tilde{L}_{k}\right) \\
k=1 \text { to } 4\end{array}$ & $\begin{array}{c}\beta_{k}, k=1 \text { to } 4 \\
(x=15)\end{array}$ & Ranking \\
\hline$p_{1}: 1-2-4-6-8$ & $\tilde{L}_{1}:(8,15,21)$ & 1 & 1 \\
\hline$p_{2}: 1-2-4-7-8$ & $\tilde{L}_{2}:(9,14,21)$ & 0.99 & 2 \\
\hline$p_{3}: 1-3-6-8$ & $\tilde{L}_{3}:(5,13,17)$ & 0.93 & 4 \\
\hline$p_{4}: 1-3-5-7-8$ & $\tilde{L}_{4}:(6,13,19)$ & 0.95 & 3 \\
\hline
\end{tabular}

Path $p_{1}: 1-2-4-6-8$ is identified as the fuzzy critical path, since it has the maximum Beta possibility distribution function $(=1)$ and the corresponding fuzzy critical path length is $\tilde{L}_{1}:(8,15,21)$.

\subsection{Procedure for Fuzzy Critical Path Problem Based on Acceptability Index for TFNs}

Step 1 and Step 2: Same as in Procedure 3.2

Step 3: Calculate $\tilde{L}_{\max }$ using Definition 6

Step 4: Calculate the Acceptability Index between $\tilde{L}_{\max }$ and $\tilde{L}_{k}$ (i.e.) $A\left(\tilde{L}_{\max }>\tilde{L}_{k}\right)$ using Definition $12, k=1$ to $m$.

Step 5: The path having the maximum Acceptability Index is identified as the Fuzzy Critical Path and the corresponding path length is the Fuzzy Critical Path length. 


\section{Numerical Example 3}

For Figure 4, the results of the network is given in the below Table 5 .

Table 5: Results of the Network

\begin{tabular}{|c|c|c|c|}
\hline $\begin{array}{c}\text { Paths }\left(p_{k}\right) \\
k=1 \text { to } 4\end{array}$ & $\begin{array}{c}\text { Path lengths }\left(\tilde{L}_{k}\right) \\
k=1 \text { to } 4\end{array}$ & $\begin{array}{c}A\left(\tilde{L}_{\max }>\tilde{L}_{k}\right) \\
k=1 \text { to } 4 \\
\tilde{L}_{\max }=(9,15,21)\end{array}$ & Ranking \\
\hline$p_{1}: 1-2-4-6-8$ & $\tilde{L}_{1}:(8,15,21)$ & 1 & 1 \\
\hline$p_{2}: 1-2-4-7-8$ & $\tilde{L}_{2}:(9,14,21)$ & 0.92 & 2 \\
\hline$p_{3}: 1-3-6-8$ & $\tilde{L}_{3}:(5,13,17)$ & 0.8 & 4 \\
\hline$p_{4}: 1-3-5-7-8$ & $\tilde{L}_{4}:(6,13,19)$ & 0.83 & 3 \\
\hline
\end{tabular}

Path $p_{1}: 1-2-4-6-8$ is identified as the fuzzy Critical path, since it has the maximum Acceptability Index $(=1)$ and the corresponding Fuzzy Critical Path Length is $\tilde{L}_{1}:(8,15,21)$.

Here $A\left(\tilde{L}_{\max }>\tilde{L}_{1}\right)=1$, hence $\tilde{L}_{\max }=(9,15,21)$ is said to be totally dominating over $\tilde{L}_{1}:(8,15,21)$.

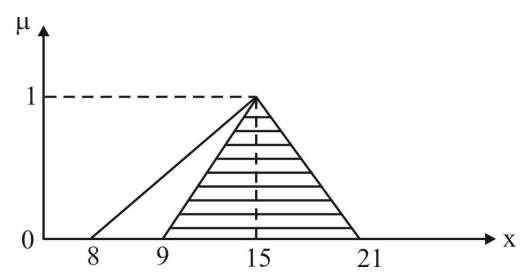

Figure 5: Totally Dominating

$0<A\left(\tilde{L}_{\max }>\tilde{L}_{k}\right)<1$, for $k=2$ to 4 . Hence $\tilde{L}_{\max }$ is said to be partially dominating over $L_{k}, k=2$ to 4 .

\subsection{Procedure for Fuzzy Critical Path Method Based on Metric Distance for TFNs}

Step 1 and Step 2: Same as in Procedure 3.2

Step 3: Calculate the Metric distance for each possible path lengths $\tilde{L}_{k}$ (i.e.) $D\left(\tilde{L}_{k}, 0\right), k=1$ to $m$ using Definition 15 . 

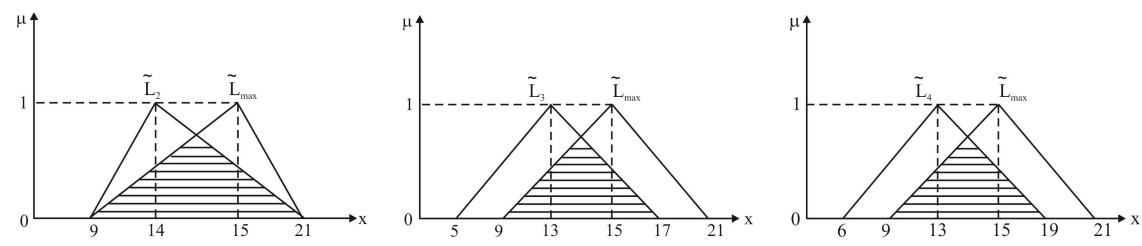

Figure 6: Partially Dominating

Step 4: The path having the maximum metric distance is identified as the Fuzzy Critical Path and the corresponding path length is the Fuzzy Critical Path length.

\section{Numerical Example 4}

For Figure 4, the results of the network is given in the below Table 6 .

Table 6: Results of the Network

\begin{tabular}{|c|c|c|c|}
\hline $\begin{array}{c}\text { Paths }\left(p_{k}\right) \\
k=1 \text { to } 4\end{array}$ & $\begin{array}{c}\text { Path lengths }\left(\tilde{L}_{k}\right) \\
k=1 \text { to } 4\end{array}$ & $\begin{array}{c}D\left(\tilde{L}_{k}, 0\right) \\
k=1 \text { to } 4\end{array}$ & Ranking \\
\hline$p_{1}: 1-2-4-6-8$ & $(8,15,21)$ & 21.53 & 1 \\
\hline$p_{2}: 1-2-4-7-8$ & $(9,14,21)$ & 21.09 & 2 \\
\hline$p_{3}: 1-3-6-8$ & $(5,13,17)$ & 17.68 & 4 \\
\hline$p_{4}: 1-3-5-7-8$ & $(6,13,19)$ & 18.80 & 3 \\
\hline
\end{tabular}

Path $p_{1}: 1-2-4-6-8$ is identified as the Fuzzy Critical Path, since it has the maximum metric distance $(=21.53)$ and the corresponding Fuzzy Critical Path length is $\tilde{L}_{1}=(8,15,21)$.

\section{Grade of Membership for the Critical Path}

Now we find the grade of membership for the critical path 1-2-4-6-8 so that the project network operation can be completed at the scheduled time. 
The membership function of $(2,3,4)$ is

$$
\mu_{D_{12}}(x)= \begin{cases}\frac{x-2}{1}, & 2 \leq x \leq 3 \\ 1, & x=3 \\ \frac{4-x}{1}, & 3 \leq x \leq 4\end{cases}
$$

$\alpha$-cut of $D_{12}=[\alpha+2,4-\alpha]$

The membership function of $(1,3,5)$ is

$$
\mu_{D_{24}}(x)= \begin{cases}\frac{x-1}{2}, & 1 \leq x \leq 3 \\ 1, & x=3 \\ \frac{5-x}{2}, & 3 \leq x \leq 5\end{cases}
$$

$\alpha$-cut of $D_{24}=[2 \alpha+1,5-2 \alpha]$

The membership function of $(3,4,6)$ is

$$
\mu_{D_{46}}(x)= \begin{cases}\frac{x-3}{1}, & 3 \leq x \leq 4 \\ 1, & x=4 \\ \frac{6-x}{2}, & 4 \leq x \leq 6\end{cases}
$$

$\alpha$-cut of $D_{46}=[\alpha+3,6-2 \alpha]$

The membership function of $(2,5,6)$ is

$$
\mu_{D_{68}}(x)= \begin{cases}\frac{x-2}{3}, & 2 \leq x \leq 5 \\ 1, & x=5 \\ \frac{6-x}{1}, & 5 \leq x \leq 6\end{cases}
$$

$\alpha$-cut of $D_{68}=[3 \alpha+2,6-\alpha]$

The $\alpha$-cut of the critical path $1-2-4-6-8$ is $[7 \alpha+8,21-6 \alpha]$.

$\therefore$ The membership function of the fuzzy critical path (FCP) is

$$
\mu_{F C P}(x)= \begin{cases}\frac{x-8}{7}, & 8 \leq x \leq 15 \\ 1, & x=15 \\ \frac{21-x}{6}, & 15 \leq x \leq 21\end{cases}
$$




\section{Results and Discussions}

One way to verify the solution obtained is to make an exhaustive comparison:

For Figure 4, various ranking methods are applied to identify the Fuzzy Critical Path. It was found that the results obtained through 4 procedures remains the same. We have shown the Numerical examples to compare our proposed method with the existing method [9].

\section{Conclusion}

Fuzzy critical path and fuzzy critical path length are the useful information for the project managers to make decision in planning and scheduling the complex projects. In this paper, new approaches in the form of ranking methods are introduced to identify the fuzzy critical path. It is also found that the result obtained in this paper coincides with the existing earlier result which reveals the proposed method is effective in determining the critical path in fuzzy sense.

\section{References}

[1] M. Bhowmik, M. Pal and A. Pal, Circulant Triangular fuzzy number matrices, Journal of Physical Sciences, 12 (2008), 141-154.

[2] M. Blue, B. Bush and J. Puckett, Unified approach to fuzzy graph problems, Fuzzy Sets and Systems, 125 (2002), 355-368.

[3] S. Chanas and J. Kamburowski, The use of fuzzy variables in PERT, Fuzzy Sets and Systems, 5 (1981), 11-19.

[4] S. Chanas P. and Zielinski, Critical Path analysis in the network with fuzzy activity times, Fuzzy Sets and Systems, 122 (2001), 195-204.

[5] T.C. Han, C.C. Chung and G.S. Liang, Application of fuzzy critical path method to airport's cargo ground operation systems, Journal of Marine Science and Technology, 14, No. 3 (2006), 139-146.

[6] Kwang. H. Lee, First Course on Fuzzy Theory and Applications, Springer Private Limited, India (2005).

[7] G.S. Liang and T.C. Han, Fuzzy Critical Path for project Network, Information and Management Sciences, 15, No. 4 (2004), 29-40. 
[8] S.H. Nasution, Fuzzy Critical Path Method, IEEE Trans. System Man Cybernet, 24 (1994), 48-57.

[9] V. Sireesha and N. Ravi Shankar, A new approach to find Total Float time and critical path in a fuzzy project network, International Journal of Engineering Science and Technology, 2, No. 4 (2010), 600-609.

[10] L. Sujatha and R. Sattanathan, Fuzzy Longest Path Problem in an acyclic digraph, International Review of Fuzzy Mathematics, 4, No. 1-2 (2009), $1-9$.

[11] A.I. Slyeptsov and T.A. Tyshchuk, A method of computation of characteristics of operations in a problem of fuzzy network, Cybernetics and Planning and Management System Analysis, 39, No. 3 (2003), 367-378.

[12] L.A. Zadeh, Fuzzy Sets, Information and Control, 8 (1965), 138-353.

[13] L.A. Zadeh, The concept of a linguistic variable and its application to approximate reasoning, Part 1, 2 and 3, Information Sciences, 8 (1975), 199-249, 9 (1976), 43-58. 